https://helda.helsinki.fi

Reporting cultures on 60 minutes : missing the Finnish line in an American newscast

\title{
Levo-Henriksson, Ritva
}

2019-01-02

Levo-Henriksson, R 2019 , ' Reporting cultures on 60 minutes : missing the Finnish line in an American newscast ' , Language and Intercultural Communication, vol. 19 , no. 1 , pp. 113-115 . https://doi.org/10.1080/14708477.2017.1309728

http://hdl.handle.net/10138/311078

https://doi.org/10.1080/14708477.2017.1309728

acceptedVersion

Downloaded from Helda, University of Helsinki institutional repository.

This is an electronic reprint of the original article.

This reprint may differ from the original in pagination and typographic detail.

Please cite the original version. 
Reporting Cultures on 60 Minutes: Missing the Finnish Line in an American Newscast, by Donal Carbaugh and Michael Berry, New York and London, Routledge, 2017, 116 pp., £ 19.99 (paperback), ISBN 978-1138-19105-1

In reporting cultures the book covers two layers. As the authors describe in their prologue, p. x, at one level, the exploration focuses on "the act of reporting about culture" which means one's own and other's culture. The second level demonstrates, how the reports are constructed "as deeply cultural forms" which are based on a person's discursive habits and their meanings. Thus, the book's focus is particularly on the ways cultural discourses constitute shared identities, proper style of conduct, and ways of relating people to one another, which can lead to misinterpretation across cultures. The starting point of the exploration in the book is the popular US televised news program, 60 Minutes, and especially its segment "Tango Finlandia," a broadcast report on Finnish culture in which an American journalist interviews and culturally voices over Finnish speech. The segment provides a rewarding reminder for researchers, professors, lecturers, and students majoring in communication as well as any readers motivated to better understand why they are/might be talking about self when talking about others.

The book is divided into eight chapters, the purpose of which is to lead a reader into the reality of reporting on different cultures while exploring their own. The five main chapters explore: (a) the focal text of television news as cultural discourse, (b) the discursive structuring within the televised text, (c) cultural discourses about and in the televised text by focusing on how participants present their culture to others and another's culture to themselves (chapters 4,5, and 6; concluding chapters 7 and 8).

The first chapter introduces the guiding theory for studying 'reporting on different cultures' and the ways different cultures are constructed. The guiding theory of the inquiry is a cultural discourse theory with a focus on discovering, describing, interpreting, comparatively analyzing, and critically assessing communication as formatives of sociocultural environments (Carbaugh, 1990, 2007). During the investigative procedure the primary data is taken from responses to "Tango Finlandia" and communication examples in everyday life. This theoretical goal supports understanding of cultural philosophies of communication. Its primary theoretical concern is a model of communication, which reveals the cultural features of everyday practices. The book's cultural model "suggests that television texts be understood as parts of historically based system of words, phrases, visual images, sequences, forms, norms, and their meanings" (p. 8).

Chapter two presents the journalistic practice of reporting culture by introducing the American television news magazine 60 Minutes and its special segment "Tango Finlandia." The introduction includes a detailed transcript of the original broadcast segment. It also contains the Finnish subtitles used in the Finnish broadcast. The researchers ponder at the 60 Minutes' popularity as "the most successful television program ever broadcast" (p.11). They characterize the nature of segments as stories, and especially reporter-based detective stories, leaning on "consensus narrative" (Thorburn, 1993). The researchers argue, how these kinds of features easily create difficulties in today's multicultural worlds.

In Chapter three the authors examine the discursive structuring in the televised text "Tango Finlandia" itself. This segment can be interpreted as "entertaining, apparently informative, and deeply intriguing" (p. 30). The segment includes language produced by American speakers of English (a 60 Minutes correspondent and an American journalist in Helsinki) and Finnish speakers of English. The segment also includes American speakers' characterizations of Finns and Finland, and the Finnish speakers' characterizations of Finns and Americans. The researchers discuss three concepts: "echoing structure," "parallel voices," and "double vision," and demonstrate how communication between an American speaker and a Finnish speaker was a contra-voicing of the matters discussed rather than an echo across cultures. Thus, the echoing structure is eventually an illusion. As a second larger discursive form, Carbaugh and Berry discuss the document's "problem-response-puzzle" form, especially for American or other non-Finnish viewers. 
Chapter four introduces examples of American astonishment about Finns immediately after they were introduced to be inexpressive, sad and shy in "Tango Finlandia." The chapter diagnoses this portrayal as a problem and offers some remedies for it. The researchers argue that this discourse reflects more about one's own cultural frame of reference without awareness of how "the other is cast as a negation of self through the words and images which contrast other with one's presumed self” (p. 49).

Chapter five deals with the Finnish discourse in and about the televised episode. A common Finnish response was should we laugh or cry? Different levels of frustration came via the commentator's negative comments about Finnish ways of living and not communicating while laughter also came via responses to examples of Finnish self-deprecating jokes in "Tango Finlandia." The researchers found deep emotional ambivalence hidden in the relationship between laughing and irritation or anger. This form of humor requires the knowledge of serious aspects of everyday Finnish life including this form of humor itself, and also the acknowledgement of how it playfully distorts serious realities, e.g. anger appeared during discussion when Finnish cultural idiosyncrasies, e.g. self-deprecating humor, was misunderstood as serious or when distorted and caricatured as mistaken truth about Finnish behavior. The researchers argue that the exploration of the Finnish discourse reveals that the model of identity at play is both factual and fictional, yet known properly only by insiders. As such, "the discourse crafts and affirms unique premises about Finnish personhood, actions, relations, and feelings, in contrast to unknowing others" (p. 65).

Chapter six deepens a reader's understanding of the Finnish discourse in and about the televised text with examples from Finnish students' and the authors' own communication experiences with others. This chapter especially proves the researchers' in-depth fieldwork and knowledge of Finnish communication behavior. They introduce quietude and thoughtfulness as two important features "in the expression of Finnishness". As they ponder about a Finnish "natural way of being" and the elements in this code, they make the central premises more explicit. They interpret quiet moments as periodical parts of social and interpersonal life and emphasize the skill of watching and listening to the other as well as speaking only when one has something worthy to say.

In chapter seven the researchers explicate the intercultural process by formulating a seven stage model, which describes the typical working of the process and how it can be moved further in productive directions. They clarify how and why the discourses had operated within a contrastive form which means noticing and speaking about the other as a contrast with self in different ways during the first six stages. The goal of the seventh stage is to move beyond contrastive discourse towards enriched comparative discourses of self and other.

The final chapter sums up five basic findings in the book. Given the intercultural dynamics of our global challenges, the goal of this book is to bring more awareness of how we are trapped by our own cultural frames of reference when interpreting differences with others. Therefore, this book belongs among the "musts" for many kinds of readers: academics, not only communication scholars, journalists, educators, students majoring in communication as well as anyone who is concerned about the power of stereotyping and misinterpretation across cultures and, most important of all, motivated to improve their skills for understanding others. Throughout their research for the book, Carbaugh and Berry demonstrate their wide, deep and thorough knowledge relating to researching intercultural communication, which includes theoretical elaboration and a command of large and rich data. In this book these two elements go together beautifully. This book also proves how the collaboration of two scholars sharing a similar cultural background and academic experience in two different countries can create a basis for developing deep understanding of the culture and communication in both countries.

This book creates awareness of a challenging intercultural communication route that all readers can benefit from in the future. The book demonstrates how "Tango Finlandia's traffic signs for navigating through 
Finnish culture led that media into its own cultural ditch off the Finnish roads. This message was not limited to the media. We often interpret others via our own perspective. Driving skills on a different cultural road requires development of ability to interpret communication signs via the cultural view of the other. The authors of this book have convincingly demonstrated why staying on an intercultural route toward better intercultural communication is difficult, how moving on the route is possible, and, to sum up, why we need to put our own cultural mirror aside in order to drive on an intercultural route towards discovery and creation of brighter prospects in global intercultural contexts.

\section{References}

Carbaugh, D. (ed.). (1990). Cultural Communication and Intercultural Contact. Hillsdale, NJ: Lawrence Erlbaum Publishers.

Carbaugh, D. (2007). Cultural discourse analysis: The investigation of communication practices with special attention to intercultural encounters. Journal of Intercultural Communication Research, 36, 167-182. Thorburn, R. (1993). Don Hewitt's durable hour. Columbia Journalism Review, September/October.

Ritva Levo-Henriksson

University of Helsinki

ritva.levo-henriksson@helsinki.fi 